\title{
DIGESTÃo FOTOQUÍMICA, ASSISTIDA POR MICROONDAS, DE ÁGUAS NATURAIS: APLICAÇÃO EM ESTUDOS DE PARTIÇÃO E ESPECIAÇÃO DO COBRE
}

Fernando F. Sodré, Patricio G. Peralta-Zamora e Marco T. Grassi*

Departamento de Química, Universidade Federal do Paraná, CP 19081, 81531-990 Curitiba - PR

Recebido em 14/7/03; aceito em 8/3/04; publicado na web em 19/7/04

\begin{abstract}
MICROWAVE-ASSISTED PHOTOCHEMICAL DIGESTION OF NATURAL WATERS: APPLICATION IN PARTITION AND SPECIATION STUDIES OF COPPER. The efficiency of a new procedure for the digestion of natural waters, based on a microwave-activated photochemical reactor was evaluated in this work. Fluorescence spectra showed a $99 \%$ reduction in the emission of a $40 \mathrm{mg} \mathrm{L}^{-1}$ humic acid solution after $15 \mathrm{~min}$ of UV irradiation. In the presence of $\mathrm{H}_{2} \mathrm{O}_{2}$, only 3 min were necessary to accomplish a reduction of almost $100 \%$ in the emission and $6 \mathrm{~min}$ to reduce the concentration of dissolved organic carbon by 95\%. The copper recovery from synthetic samples containing commercial humic acid, from soil suspensions, as well as from natural waters varied between 91.5 and $106.6 \%$. The digestion of dissolved and unfiltered samples was successfully accomplished in 6 and $12 \mathrm{~min}$, respectively. No contaminations or sample losses were observed. Results of copper speciation in natural waters showed that this metal is predominantly bound to natural ligands. Only $3-6 \%$ of the total recoverable copper is present in the labile form.
\end{abstract}

Keywords: natural water digestion; speciation; partitioning.

\section{INTRODUÇÃO}

A partição de metais entre as fases dissolvida e particulada exerce uma influência importante sobre seu transporte, reatividade e biodisponibilidade para a biota aquática. Mais do que isso, sabe-se hoje que a toxicidade de metais não pode ser atribuída, exclusivamente, à concentração total dissolvida. Conseqüentemente, o conhecimento da especiação química de metais é um aspecto determinante na avaliação de seu verdadeiro impacto ambiental ${ }^{1}$.

Uma variedade de ligantes orgânicos e inorgânicos exerce um papel fundamental no controle da partição e da especiação de espécies metálicas em sistemas aquáticos naturais ${ }^{1-4}$. Uma das principais propriedades destes ligantes é a capacidade de formar complexos estáveis com metais e, em virtude disso, reduzir o potencial tóxico destas espécies ${ }^{1,5}$. No material particulado em suspensão, estes ligantes compreendem uma grande variedade de compostos, geralmente, minerais, partículas orgânicas incluindo substâncias húmicas, microorganismos e tecidos biológicos e partículas inorgânicas cobertas por material orgânico ${ }^{3,4}$. Na fração dissolvida, os principais compostos responsáveis pela complexação de espécies metálicas são os compostos orgânicos em solução, principalmente as substâncias húmicas aquáticas.

A quantificação dos teores de metais, tanto na fração dissolvida, quanto na amostra in natura, contendo o material particulado em suspensão, está associada a uma etapa de digestão que leve à solubilização da espécie de interesse, seja pela completa destruição dos ligantes naturais, ou ainda pela degradação parcial de compostos interferentes ${ }^{6}$. A presença da matéria orgânica dissolvida, por exemplo, pode resultar em interferências na quantificação de metais quando se emprega espectrometria de absorção atômica, quimiluminescência e técnicas voltamétricas de redissolução ${ }^{7-9}$. Segundo van den $\operatorname{Berg}^{10}$, a presença da matéria orgânica em análises voltamétricas pode comprometer a determinação da concentração de metais por meio da formação de metalo-complexos estáveis e inertes

*e-mail: mtgrassi@quimica.ufpr.br à detecção, além de competir com a espécie de interesse pela superfície do eletrodo de trabalho, reduzindo assim a sensibilidade da medida e provocando o aparecimento de sinais interferentes.

São muitos os procedimentos propostos na literatura para a digestão de amostras de águas naturais ${ }^{7-13}$. A digestão pode ser conduzida em batelada, com o emprego de recipientes abertos ou fechados ${ }^{14}$, ou ainda de maneira contínua ${ }^{6,15,16}$. Independentemente do tipo de digestão, estes procedimentos baseiam-se, essencialmente, na ação de uma fonte ininterrupta de aquecimento em associação ao poder oxidante de um componente que age diretamente na amostra. Temperaturas elevadas podem ser obtidas empregando-se chapas aquecedoras, blocos digestores ou fornos microondas. Neste último caso, a magnitude do aquecimento depende exclusivamente das propriedades dielétricas das moléculas presentes na amostra ${ }^{17}$. Além disso, a velocidade e a eficiência do aquecimento dielétrico são superiores aos obtidos por fontes convencionais ${ }^{18}$. $\mathrm{O}$ aquecimento por microondas também resulta em um aumento na velocidade analítica e um incremento nas condições de digestão, ao mesmo tempo em que reduz a formação de subprodutos originados pelo superaquecimento $^{14,19}$. A utilização de radiações na faixa de microondas, aliada ao poder oxidante de diversos reagentes, tem sido muito freqüente em química analítica ${ }^{20,21}$. Substâncias como o ácido nítrico, o ácido perclórico, o ácido hipocloroso, o hipoclorito de sódio, entre outras, têm um excepcional poder de oxidação e vêm sendo largamente utilizadas para a destruição de matrizes orgânicas interferentes ${ }^{22}$. Entretanto, em análises que envolvem a determinação da concentração de metais-traço, existe uma grande preocupação com relação ao processamento e adição de reagentes à amostra ${ }^{23,24}$. Devido às baixas concentrações da espécie de interesse $\left(\mathrm{nmol} \mathrm{L} \mathrm{L}^{-1}\right.$ a pmol L-1), a adição de reagentes pode ser uma fonte real de contaminação, além de contribuir para a diluição da amostra ${ }^{8}$. Em alguns casos, a contaminação gera erros superiores a duas ordens de magnitude em relação à concentração dos metais presentes na amostra ${ }^{24}$.

Uma alternativa bastante eficiente para a destruição da matéria orgânica dissolvida presente em águas naturais consiste na utilização de processos fotoquímicos de oxidação ${ }^{24-26}$. Estes processos ba- 
seiam-se na geração in situ do radical hidroxila $\left({ }^{\circ} \mathrm{OH}\right)$, de elevado poder de oxidação $\left(\mathrm{E}^{0}=2,8 \mathrm{~V}\right)$, que é capaz de romper ligações de caráter covalente e induzir a mineralização completa dos ligantes orgânicos presentes na amostra. Além disso, este procedimento proporciona uma redução significativa no tempo de digestão e nas quantidades de reagentes empregados ${ }^{24,26}$. A irradiação da amostra com luz ultravioleta pode motivar o aparecimento de ${ }^{\circ} \mathrm{OH}$ pela simples fotólise da matéria orgânica dissolvida. Entretanto, uma digestão mais efetiva pode ser obtida pela adição de pequenas quantidades de peróxido de hidrogênio, por exemplo.

O efeito sinérgico da utilização do aquecimento por microondas e da irradiação da amostra com luz ultravioleta pode representar uma redução significativa no tempo de digestão de amostras de águas naturais para análise de metais-traço $\mathrm{O}^{21,24}$. A combinação entre os dois métodos torna-se mais eficiente quando a radiação ultravioleta é gerada por microondas a partir de uma lâmpada ou um reator exposto a um campo eletromagnético ${ }^{17,27-28}$.

Este trabalho propõe o emprego de um método alternativo para a digestão de amostras de águas naturais utilizando um reator fotoquímico ativado por microondas. O procedimento foi testado em estudos envolvendo a partição e a especiação química do cobre em amostras sintéticas, preparadas em laboratório, assim como em amostras de águas naturais.

\section{PARTE EXPERIMENTAL}

\section{Reator fotoquímico ativado por microondas}

O procedimento de digestão proposto neste trabalho baseia-se na ação da radiação ultravioleta gerada em um reator ativado por microondas. O reator UV LAB EL 10, comercializado pela Umex (Dresden, Alemanha), possui capacidade para processar até $15 \mathrm{~mL}$ de amostra e é constituído por dois corpos cilíndricos concêntricos de diferentes diâmetros. Um esquema representativo do reator fotoquímico é mostrado na Figura 1. O corpo interno é de quartzo de elevada permeabilidade à radiação UV, enquanto que o corpo externo é constituído de vidro de borossilicato, de baixa permeabilidade ao UV. O espaço entre ambos é preenchido com vapor de mercúrio à baixa pressão. A energia gerada em um forno microondas doméstico é suficiente para promover a excitação dos átomos de mercúrio, que passam a emitir radiação UV de elevada intensidade no comprimento de onda de $254 \mathrm{~nm}$.

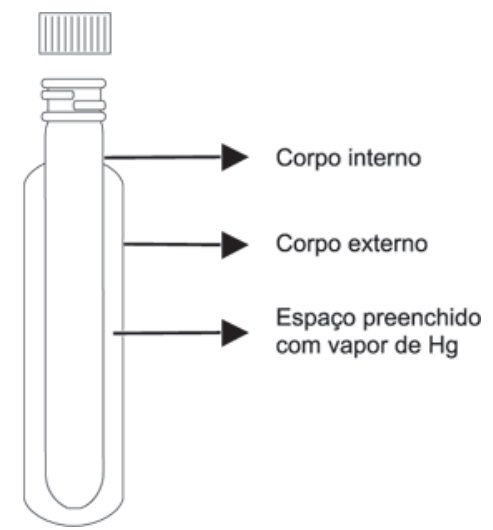

Figura 1. Representação esquemática do reator fotoquímico UV LAB EL 10 utilizado nos experimentos de digestão

\section{Otimização do procedimento de digestão}

Inicialmente, foi preparada uma solução de ácido húmico comercial (Aldrich - 35\% de C) a $40 \mathrm{mg} \mathrm{L}^{-1}$, em água do tipo Milli-Q
(Millipore). Uma alíquota de $15 \mathrm{~mL}$ desta solução foi transferida para o reator que foi então inserido, sem a tampa, no forno microondas (Electrolux ME 900). Durante a digestão, foram empregados ciclos de até 3 min de irradiação, utilizando-se a potência máxima nominal do forno microondas, ou seja, $900 \mathrm{~W}$. Um béquer contendo $1 \mathrm{~L}$ de água foi colocado no forno juntamente com o reator, para dispersar o calor gerado e evitar perdas por ebulição da amostra. Entre cada ciclo de irradiação a água contida no béquer foi trocada e o reator permaneceu em banho de gelo durante cerca de $5 \mathrm{~min}$. A degradação do ácido húmico foi avaliada através de medidas de fluorescência, realizadas em um espectrofotômetro de emissão de fluorescência (Hitachi F4500), utilizando os comprimentos de onda de excitação e emissão de 315 e $440 \mathrm{~nm}$, respectivamente ${ }^{9}$. A eficiência do processo de digestão foi avaliada na ausência e na presença de peróxido de hidrogênio. Neste caso, foram adicionados $12 \mu \mathrm{L}$ de $\mathrm{H}_{2} \mathrm{O}_{2} 30 \%$ (Biotec). Em algumas amostras também foram determinados os teores de carbono orgânico total (Shimadzu TOC5000) durante o procedimento de digestão.

\section{Testes de recuperação}

A eficiência da digestão também foi avaliada a partir de testes de recuperação de cobre em soluções contendo ácido húmico comercial e em suspensões preparadas com um Latossolo Vermelho distroférrico $(\mathrm{LV} d)$ de características químicas, físicas e mineralógicas bem definidas ${ }^{29}$.

Alíquotas de uma solução $20 \mathrm{mg} \mathrm{L}^{-1}$ de ácido húmico foram enriquecidas com 5, 10 e $20 \mu \mathrm{g} \mathrm{L}^{-1}$ de cobre (Tritisol, Merck) e mantidas sob agitação durante $24 \mathrm{~h}$. Em seguida, foram acidificadas para $\mathrm{pH}<2$ com $\mathrm{HNO}_{3}$ (Merck) e digeridas durante 6 min na presença de $12 \mu \mathrm{L}$ de $\mathrm{H}_{2} \mathrm{O}_{2}$. As suspensões foram preparadas empregando-se 10,20 e $50 \mathrm{mg} \mathrm{L}^{-1}$ de solo, previamente moído em gral de porcelana e passado em peneira de $0,074 \mathrm{~mm}$ para uniformizar a dimensão dos agregados e evitar diferenças na sorção de metais ${ }^{29}$. As suspensões foram então enriquecidas com 10, 20 e $50 \mu \mathrm{g} \mathrm{L}^{-1}$ de cobre e mantidas sob agitação durante $24 \mathrm{~h}$. Em seguida, foram acidificadas para $\mathrm{pH}<2$ e digeridas durante $12 \mathrm{~min}$ na presença de $24 \mu \mathrm{L}$ de $\mathrm{H}_{2} \mathrm{O}_{2}$, sendo que $12 \mu \mathrm{L}$ foram adicionados no início e o restante, após 6 min de digestão.

A digestão também foi avaliada empregando-se amostras de águas naturais. Foram coletadas amostras de águas superficiais nos Rios Iraí e Iguaçu, em pontos localizados na Região Metropolitana de Curitiba. As amostras foram filtradas a vácuo em sistema fechado utilizando membranas de acetato de celulose (Schleicher \& Shuell), com $0,45 \mu \mathrm{m}$ de porosidade, para separar a fração dissolvida. Todo o procedimento de coleta, filtração e preparo de amostras foi baseado no uso de técnicas limpas ${ }^{22,23}$. As alíquotas reservadas para análise de cobre total dissolvido foram enriquecidas com 2,5 e $10 \mu \mathrm{g} \mathrm{L}^{-1} \mathrm{de}$ cobre e a amostra in natura, com 10, 20 e $30 \mu \mathrm{g} \mathrm{L} \mathrm{L}^{-1}$ deste metal. Após agitação, foram imediatamente acidificadas com $\mathrm{HNO}_{3}$ e submetidas à digestão no reator ativado por microondas.

A determinação dos teores totais de cobre nas amostras foi conduzida por voltametria de redissolução anódica com pulso diferencial (VRAPD), e adição de padrões. As análises voltamétricas foram executadas em um potenciostato EG\&G PAR M394, com eletrodo de mercúrio SMDE EG\&G PAR 303A.

\section{Especiação química}

A especiação química do cobre foi realizada em amostras dos rios Iraí e Iguaçu. A determinação de cobre lábil foi conduzida por VRAPD através da técnica de competição de ligantes, utilizando-se etilenodiamina (EN) como ligante sintético de competição ${ }^{30}$. Uma 
alíquota da fração dissolvida, previamente acidificada, foi digerida empregando-se a metodologia proposta neste trabalho e, em seguida, enriquecida com EN até que a concentração final do ligante de

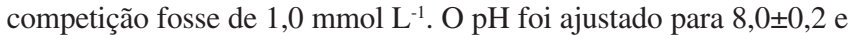
a alíquota foi mantida em repouso durante uma noite. Nesta amostra, foi determinada a corrente de intensidade máxima, aqui denominada $I_{p}^{m a ́ x}$, assim como a concentração total de cobre na fração dissolvida (CuTD) pelo método de adição de padrões. Os parâmetros da medida voltamétrica foram varredura de $-0,6$ a $0,0 \mathrm{~V}$, velocidade de varredura de $8 \mathrm{mv} \mathrm{s}^{-1}, 15 \mathrm{~min}$ de deposição e $8 \mathrm{~min}$ de purga inicial. Uma outra alíquota da fração dissolvida, inalterada e não digerida, foi submetida ao mesmo procedimento analítico utilizado para determinação voltamétrica de CuTD, exceto que o ligante de competição foi adicionado apenas a alguns segundos do fim do período de deposição. Nesta amostra foi determinada a intensidade de corrente inicial, aqui denominada $I_{p}{ }^{0}$. A concentração de cobre lábil foi finalmente calculada a partir da multiplicação do valor de CuTD pelo valor obtido pela razão $I_{p}{ }^{0} / I_{p}^{m a ́ x}$.

\section{RESULTADOS E DISCUSSÃO}

Na etapa de otimização do procedimento, a duração máxima de cada ciclo de digestão foi fixada em $3 \mathrm{~min}$. Sob estas condições, a perda de amostra por ebulição foi inferior a $0,1 \%$. Desta forma, todas as soluções foram submetidas à digestão em ciclos de até 3 min de duração.

Na Figura 2 encontram-se os espectros de fluorescência obtidos para diferentes tempos de digestão em uma solução $40 \mathrm{mg} \mathrm{L}^{-1} \mathrm{de}$
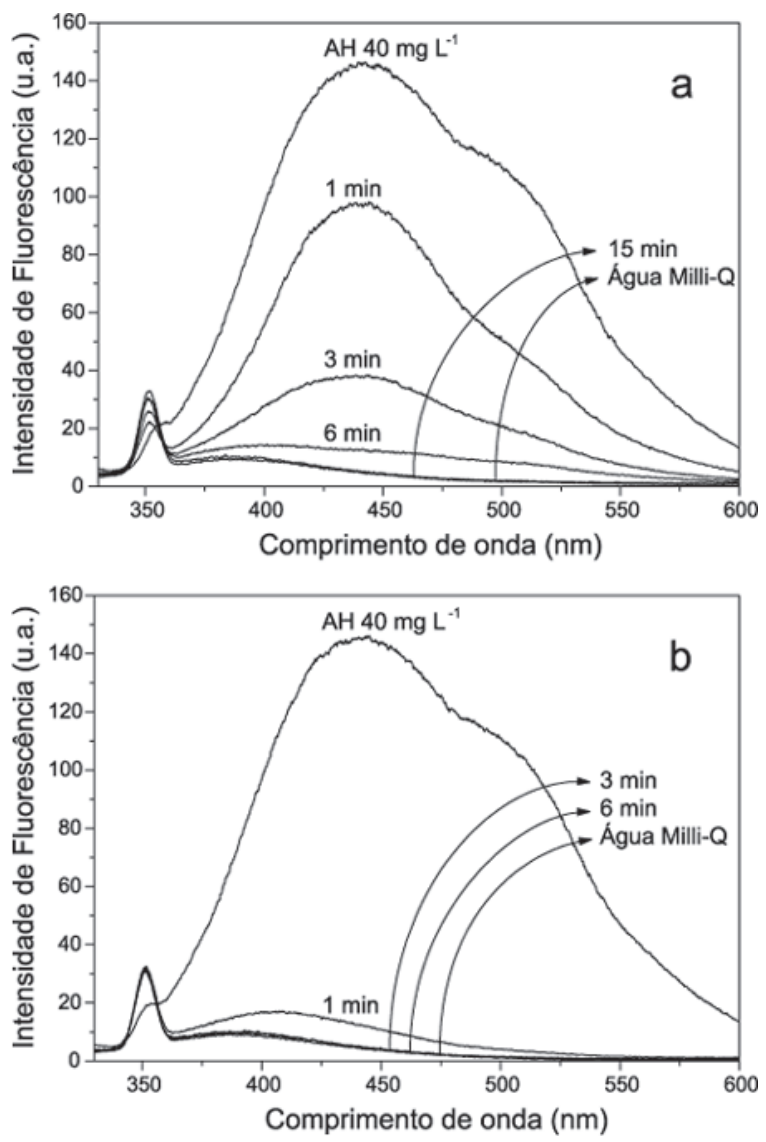

Figura 2. Espectros de emissão de fluorescência para uma solução $40 \mathrm{mg}$ $L^{-1}$ de ácido húmico na ausência (a) e na presença (b) de $\mathrm{H}_{2} \mathrm{O}_{2}$ em diferentes tempos de irradiação ácido húmico. Uma vez que as substâncias húmicas constituem os principais componentes orgânicos presentes em águas naturais, a utilização de ácido húmico comercial é recomendada como forma de mimetizar o comportamento da matéria orgânica dissolvida natural $^{9,16,25,26}$. Pode-se observar, na Figura 2a, que a intensidade de emissão apresentou uma redução de cerca de $99 \%$ após 15 min de irradiação.

O procedimento de digestão de amostras apresentado neste trabalho promoveu uma redução significativa no tempo necessário para destruição da matéria orgânica dissolvida, quando comparado com resultados presentes na literatura ${ }^{9,16}$. Para uma solução de ácido húmico a $15 \mathrm{mg} \mathrm{C} \mathrm{L}^{-1}$, Achterberg e van den Berg ${ }^{15}$ relataram a necessidade de utilizar 330 min para total destruição da amostra irradiada com luz UV gerada a partir de uma lâmpada a vapor de mercúrio. Campos e colaboradores ${ }^{9}$ avaliaram a eficiência de um reator artesanal na fotodegradação de soluções de ácido húmico a 4, 6, 8 e $12 \mathrm{mg} \mathrm{C} \mathrm{L}^{-1}$. Para a solução mais diluída, foram necessários $30 \mathrm{~min}$ para se atingir uma redução de aproximadamente $99 \%$ da emissão de fluorescência. Para as soluções mais concentradas, foram necessários até 120 min de exposição à irradiação.

Quando a solução $40 \mathrm{mg} \mathrm{L}^{-1}$ de ácido húmico foi tratada com $\mathrm{H}_{2} \mathrm{O}_{2}$ (Figura 2b), foram necessários apenas 3 min para se atingir praticamente $100 \%$ de redução da emissão de fluorescência e 6 min para uma redução superior a 95\% nos teores de carbono orgânico dissolvido. Neste caso, o tempo de digestão apresentou-se reduzido devido à fotólise direta do peróxido de hidrogênio em meio aquoso, que gera radicais ${ }^{\circ} \mathrm{OH}$ de elevada reatividade ${ }^{25-26}$. O radical hidroxila ataca uma gama de compostos orgânicos alifáticos e aromáticos com

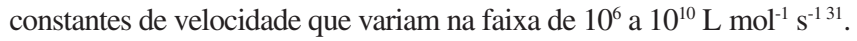
A utilização de peróxido de hidrogênio durante o procedimento mostrou-se bastante eficiente para a digestão de amostras de águas naturais. Apenas uma pequena quantidade de $\mathrm{H}_{2} \mathrm{O}_{2}$ foi necessária para reduzir o tempo de digestão em cerca de $80 \%$, sem representar uma fonte de contaminação e diluição da amostra. Além disso, após 6 min de irradiação foi observada a ausência de peróxido residual ${ }^{32}$, que pode interferir na determinação de metais em análises voltamétricas.

Um teste conduzido com o auxílio de um tubo de ensaio de borossilicato foi realizado para se comparar a eficiência da radiação UV com outros fatores, tais como radiação microondas, temperatura (cerca de $75^{\circ} \mathrm{C}$ ) e presença de $\mathrm{H}_{2} \mathrm{O}_{2}$. Tanto o reator quanto o tubo de ensaio possuem capacidade para processar cerca de $15 \mathrm{~mL}$ de amostra. A Figura 3 mostra a concentração relativa de ácido húmico, obtida pela intensidade máxima de fluorescência determinada em 440 $\mathrm{nm}$, em função dos tempos de digestão obtidos com a utilização do reator ativado por microondas e do tubo de ensaio. Na Figura 3a, observa-se que uma solução $40 \mathrm{mg} \mathrm{L}^{-1}$ de ácido húmico apresentou uma redução considerável da emissão de fluorescência utilizando o reator ativado por microondas. Para a solução contida no tubo de ensaio, a emissão permaneceu praticamente constante. Quando as soluções contendo ácido húmico foram enriquecidas com $\mathrm{H}_{2} \mathrm{O}_{2}(\mathrm{Fi}$ gura 3b), observou-se uma rápida redução inicial da emissão de fluorescência para a solução contida no reator fotoquímico ativado por microondas. Utilizando-se o tubo de ensaio, ao contrário, observou-se um aumento de cerca de $40 \%$ no sinal de fluorescência logo no início do processo.

Os resultados apresentados indicam que a radiação UV gerada pelo reator mostrou-se essencial na digestão das soluções contendo ácido húmico. Assim, fatores como radiação microondas e temperatura não foram suficientes para promover a degradação do material na mesma escala de tempo observada com a utilização do reator ativado por microondas. A presença de $\mathrm{H}_{2} \mathrm{O}_{2}$ proporcionou comportamentos diferentes em relação à emissão de fluorescência das solu- 

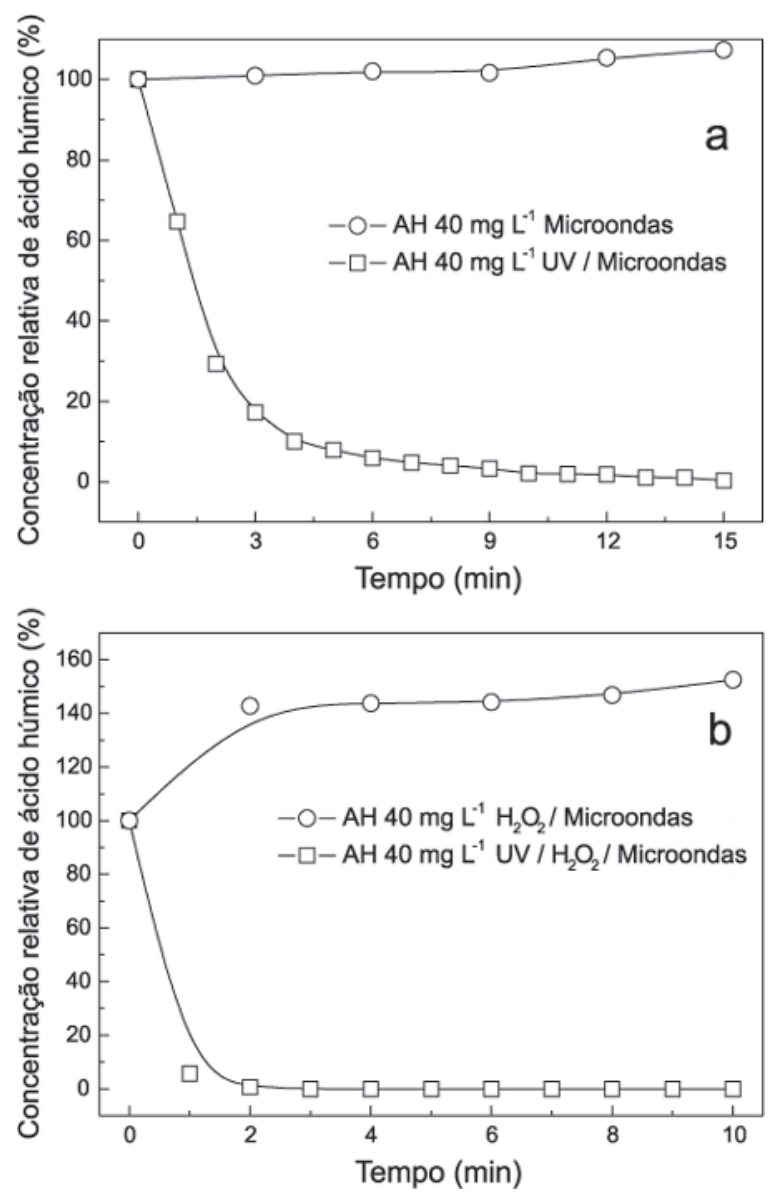

Figura 3. Concentração relativa de ácido húmico expressa como porcentagem do sinal de emissão de fluorescência em $440 \mathrm{~nm}\left(\lambda_{\text {exc }}=315 \mathrm{~nm}\right)$. (a) $\mathrm{AH} 40 \mathrm{mg} \mathrm{L} \mathrm{L}^{-1} \mathrm{e}$ (b) $\mathrm{AH} 40 \mathrm{mg} \mathrm{L^{-1 }}$ na presença de $12 \mu \mathrm{L}$ de $\mathrm{H}_{2} \mathrm{O}_{2}$. Amostras processadas em um tubo de ensaio de borossilicato ( $\bigcirc)$ e no reator fotoquímico ativado por microondas ( $\square$ )

ções contendo ácido húmico. Quando se emprega o reator fotoquímico, a radiação UV é responsável pela geração de radicais hidroxila de elevada reatividade a partir da fotólise direta do peróxido de hidrogênio. Por outro lado, o aumento do sinal de fluorescência observado para a solução processada no tubo de ensaio pode ser conseqüência do poder oxidante do $\mathrm{H}_{2} \mathrm{O}_{2}$, que degrada parcialmente a matéria orgânica gerando sub-grupamentos fluoróforos ${ }^{9}$, ou ainda pela supressão do sinal de fluorescência no início do processo.

Para testar a eficiência do reator em uma amostra de água salina, uma alíquota da solução $40 \mathrm{mg} \mathrm{L}^{-1}$ de ácido húmico foi enriquecida com uma mistura contendo $\mathrm{NaCl}, \mathrm{MgSO}_{4}$ e $\mathrm{NaHCO}_{3}$ (salinidade 34,2 ). Neste caso, foi observada uma redução superior a $97 \%$ do sinal de emissão do ácido húmico em 27 min de irradiação. Este aumento no tempo de digestão, em comparação às soluções nãosalinas, pode ser resultado da competição existente entre a matéria orgânica e o bicarbonato por radicais ${ }^{\circ} \mathrm{OH}$ gerados no processo fotoquímico ${ }^{25}$.

\section{Testes de recuperação de cobre}

Todas as determinações de cobre por VRAPD foram realizadas em triplicata, obtendo-se desvios médios inferiores a 10\%. A Tabela 1 apresenta os resultados obtidos para os testes de recuperação de cobre em soluções $20 \mathrm{mg} \mathrm{L}^{-1}$ de ácido húmico. Observa-se que em apenas 6 min de digestão foram obtidas porcentagens de recuperação de cobre na faixa de 98,8 a $103 \%$. A digestão de amostras contendo ácido húmico mostrou resultados promissores para a determinação de metais na fração dissolvida. Entretanto, a determinação do teor total de uma espécie metálica em águas naturais exige um método de digestão um pouco mais drástico, devido à presença de material particulado em suspensão. Assim sendo, a concentração de metal total recuperável é determinada na amostra in natura e, conseqüentemente, na presença de matéria orgânica dissolvida e de material particulado em suspensão. Os resultados obtidos para a determinação de cobre em suspensões preparadas com o LVd, em tempos de digestão superiores àqueles adotados para soluções contendo ácido húmico, mostraram-se satisfatórios, com percentuais de recuperação na faixa de 91,5 a 106,6\% (Tabela 2).

Amostras de águas naturais dos Rios Iraí e Iguaçu também foram analisadas com relação à recuperação de cobre. A Tabela 3 mostra os resultados obtidos para amostras coletadas em janeiro de 2002. Os parâmetros de digestão foram estabelecidos a partir dos testes de recuperação realizados em soluções contendo ácido húmico e suspensões de solo. Para determinação do cobre total recuperável foram necessários 12 min de digestão na presença de $24 \mu \mathrm{L}$ de $\mathrm{H}_{2} \mathrm{O}_{2}$ e para a digestão da fração dissolvida foram necessários apenas 6 min com a adição de $12 \mu \mathrm{L}$ de $\mathrm{H}_{2} \mathrm{O}_{2}$. Além de bons resultados com relação à recuperação de cobre $(95,4$ a $107,4 \%)$, é possível observar valores distintos entre os teores de cobre determinados nas frações dissolvidas e na amostra in natura, para ambos os rios. Os testes de recuperação de cobre mostraram resultados que possibilitam a utilização do reator fotoquímico ativado por microondas para digestão de amostras de águas naturais, sem a ocorrência de erros provenientes da adição de grandes quantidades de reagentes. Mesmo para a fração

Tabela 1. Testes de recuperação para uma solução $20 \mathrm{mg} \mathrm{L}^{-1}$ de ácido húmico comercial enriquecida com cobre $\left(\mu \mathrm{g} \mathrm{L}^{-1}\right)$ e irradiada durante 6 min na presença de $\mathrm{H}_{2} \mathrm{O}_{2}$

\begin{tabular}{ccc}
\hline$[\mathrm{Cu}]$ adic. & {$[\mathrm{Cu}]$ det. } & Rec. $(\%)$ \\
\hline 5,00 & 5,14 & 102,8 \\
10,0 & 10,4 & 103,9 \\
20,0 & 19,8 & 98,8 \\
\hline
\end{tabular}

Tabela 2. Testes de recuperação para suspensões de solo enriquecidas com cobre $\left(\mu \mathrm{g} \mathrm{L}^{-1}\right)$ e irradiadas durante 12 min na presença de $\mathrm{H}_{2} \mathrm{O}_{2}$

\begin{tabular}{|c|c|c|c|c|c|c|}
\hline \multirow[b]{3}{*}[\mathrm{Cu}]{ adic. } & \multicolumn{6}{|c|}{ Suspensões de solo $\left(\mathrm{mg} \mathrm{L}^{-1}\right)$} \\
\hline & \multicolumn{2}{|c|}{10,0} & \multicolumn{2}{|c|}{20,0} & \multicolumn{2}{|c|}{50,0} \\
\hline & {$[\mathrm{Cu}]$ det. } & Rec. $(\%)$ & {$[\mathrm{Cu}]$ det. } & Rec. $(\%)$ & {$[\mathrm{Cu}]$ det. } & Rec. $(\%)$ \\
\hline 10,0 & 9,84 & 98,4 & 9,58 & 95,8 & 9,93 & 99,3 \\
\hline 20,0 & 18,2 & 91,5 & 20,8 & 104,1 & 20,4 & 101,9 \\
\hline 50,0 & 51,4 & 102,8 & 52,1 & 104,2 & 53,3 & 106,6 \\
\hline
\end{tabular}


particulada, onde os componentes inorgânicos são pouco solúveis em água e são normalmente dissolvidos por meio de processos mais drásticos ${ }^{22}$, o procedimento de digestão mostrou-se eficiente.

Em amostras de águas naturais, grande parte do metal encontrase fortemente associado à matéria orgânica, sendo que em materiais inorgânicos, tais como óxidos e silicatos do tipo 1:1, acredita-se que o metal se encontra preferencialmente adsorvido por forças de ligação predominantemente eletroativas e, portanto, dependentes do $\mathrm{pH}^{29}$. Neste caso, a redução do $\mathrm{pH}$ da amostra para valores inferiores ao ponto de carga zero destes componentes é suficiente para promover a dissolução de grande parte dos metais associados à fração particulada. Assim, apenas a destruição da matéria orgânica e a redução do $\mathrm{pH}$ podem ser suficientes para a determinação de metais por voltametria de redissolução, tanto para a fração dissolvida, quanto para a amostra in natura.

Os resultados obtidos para a partição do cobre em amostras dos rios Iraí e Iguaçu encontram-se na Tabela 4. Os teores de cobre obtidos neste trabalho são compatíveis com dados apresentados na literatura $^{9,30}$. Para o Rio Iguaçu, observam-se níveis superiores de cobre total recuperável e dissolvido, respectivamente 6,63 e $2,86 \mu \mathrm{g} \mathrm{L}^{-1}$, em comparação às concentrações determinadas para o Rio Iraí, que são iguais a 2,37 $\mu \mathrm{g} \mathrm{L}^{-1}$ para a fração total recuperável e $1,48 \mu \mathrm{g} \mathrm{L}^{-1}$ para o cobre presente na fração dissolvida. Os resultados contidos na Tabela 4 também permitem observar comportamentos distintos quanto a partição do cobre entre o material particulado em suspensão e a fração dissolvida, quando são comparados os dois rios. Para o Rio Iguaçu, cerca de $57 \%$ do cobre encontra-se associado ao material particulado e aproximadamente $43 \%$ permanece na fração dissolvida. No Rio Iraí observa-se um comportamento contrário, onde a maior parte do cobre, cerca de $62 \%$, encontra-se presente na fração dissolvida, enquanto $38 \%$ estão ligados ao material particulado em suspensão. Estes resultados refletem comportamentos típicos observados nestes corpos de água ${ }^{33}$ e também estão de acordo com aqueles encontrados na literatura, nos quais os componentes presentes na fração dissolvida podem ser responsáveis pela complexação de 40 a $50 \%$ do cobre recuperável presente na amostra ${ }^{34}$. No caso do Rio Iraí, o elevado teor de cobre na fração dissolvida pode ser conse- qüência da presença de compostos coloidais que são computados nesta fração, embora tenham características de material sólido ${ }^{1,2,33}$.

A aplicação da técnica de competição de ligantes, empregando etilenodiamina como ligante de competição ${ }^{30,33}$, permite a avaliação da especiação química do cobre em águas naturais através da detecção de uma fração denominada lábil, que corresponde ao somatório das concentrações livre e cineticamente reversíveis do metal. Os resultados obtidos para amostras típicas dos rios Iraí e Iguaçu também são mostrados na Tabela 4. É possível observar que no caso do Rio Iguaçu, aproximadamente 3\% do cobre encontra-se na forma lábil, ou seja, aquela considerada biodisponível. Para o Rio Iraí, nota-se que a fração lábil corresponde a cerca de $6 \%$ do total recuperável. A diferença de comportamento observada para o metal nos dois rios deve-se, provavelmente, às características de ambos. O Rio Iguaçu apresenta teores mais elevados de sólidos suspensos totais e também de carbono orgânico dissolvido, o que contribui para uma diminuição das concentrações lábeis do metal. Ao contrário, o Rio Iraí apresentou teores mais baixos de sólidos suspensos totais e carbono orgânico dissolvido. Tais características resultam em níveis mais elevados do cobre na fração denominada lábil.

\section{CONCLUSÕES}

O procedimento de digestão para amostras de águas naturais proposto neste trabalho mostrou-se bastante eficiente na destruição da matéria orgânica dissolvida e proporcionou igualmente bons resultados para a digestão de amostras in natura, ou seja, aquelas contendo material particulado em suspensão.

Testes de recuperação para cobre realizados em soluções contendo ácido húmico comercial, em suspensões de solo e em amostras de águas naturais apresentaram resultados satisfatórios, tanto para a fração dissolvida quanto para a amostra in natura. Os percentuais de recuperação situaram-se na faixa entre 90 e $110 \%$.

A digestão de águas naturais pôde ser realizada em um tempo de apenas 6 min no caso de amostras filtradas e de 12 min para amostras in natura. Além disso, todo o procedimento foi desenvolvido sem a ocorrência de contaminações ou perdas significativas da espé-

Tabela 3. Testes de recuperação para a fração dissolvida e para a amostra in natura de águas naturais, coletadas em janeiro de 2002, enriquecidas com cobre $\left.(\mu \mathrm{g} \mathrm{L})^{-1}\right)$

\begin{tabular}{|c|c|c|c|c|c|c|}
\hline & \multicolumn{3}{|c|}{ Fração dissolvida* } & \multicolumn{3}{|c|}{ Amostra in natura** } \\
\hline & {$[\mathrm{Cu}]$ adic. } & {$[\mathrm{Cu}]$ det. } & Rec. $(\%)$ & {$[\mathrm{Cu}]$ adic. } & {$[\mathrm{Cu}]$ det. } & Rec. $(\%)$ \\
\hline \multirow[t]{4}{*}{ Rio Iraí } & 0,00 & 3,80 & - & 0,00 & 11,2 & - \\
\hline & 2,00 & 5,80 & 100,0 & 10,0 & 20,9 & 98,5 \\
\hline & 5,00 & 9,17 & 107,4 & 20,0 & 31,5 & 101,9 \\
\hline & 10,0 & 13,4 & 95,9 & 30,0 & 42,2 & 103,5 \\
\hline \multirow[t]{4}{*}{ Rio Iguaçu } & 0,00 & 2,69 & - & 0,00 & 4,48 & - \\
\hline & 2,00 & 4,67 & 99,0 & 10,0 & 15,1 & 106,3 \\
\hline & 5,00 & 7,87 & 103,6 & 20,0 & 23,6 & 95,4 \\
\hline & 10,0 & 12,7 & 100,6 & 30,0 & 34,6 & 100,4 \\
\hline
\end{tabular}

Tabela 4. Especiação química do cobre $\left(\mu \mathrm{g} \mathrm{L}^{-1}\right)$ em águas dos Rios Iraí e Iguaçu coletadas em março de 2002

\begin{tabular}{lccccc}
\hline & CuTR & CuTD & Cu particulado & Cu complexado* & Cu lábil* \\
\hline Rio Iraí & 2,37 & $1,48(62)$ & $0,89(38)$ & $1,34(56)$ & $0,14(6)$ \\
Rio Iguaçu & 6,63 & $2,86(43)$ & $3,77(57)$ & $2,66(40)$ & $0,20(3)$ \\
\hline
\end{tabular}

CuTR - cobre total recuperável, CuTD - cobre total dissolvido. Entre parênteses, a porcentagem de cobre associado a cada fração. *Cobre presente na fração dissolvida. 
cie de interesse. De uma maneira geral, o procedimento aqui apresentado constitui-se em uma alternativa viável em estudos de partição e especiação de metais em águas naturais quando comparado com métodos convencionais de digestão.

\section{REFERÊNCIAS}

1. Allen, H. E.; Hansen, D. J.; Water Environ. Res.1996, 68, 42.

2. Benoit, G.; Rozan, T. F.; Geochim. Cosmochim. Acta. 1999, 63, 103.

3. Shi, B.; Allen, H. E.; Grassi, M.T.; Ma, H. Z.; Water Res. 1998, 32, 3756.

4. Grassi, M. T.; Shi, B.; Allen, H. E.; J. Braz. Chem. Soc. 2000, 11, 516.

5. Guo, L.; Hunt, B. J.; Santschi, P. H.; Ray, S. M.; Environ. Sci. Technol. 2001, 35, 885 .

6. Achterberg, E. P.; Braungardt, C. B.; Sandford, R. C.; Worsfold, P. J.; Anal. Chim. Acta 2001, 440, 27.

7. Guéguen, C.; Belin, C.; Thomas, B. A.; Monna, F.; Favarger, P. Y.; Dominik, J.; Anal. Chim. Acta 1999, 386, 155.

8. Florian, D.; Knapp, G.; Anal. Chem. 2001, 73, 1515.

9. Campos, M. L. A. M.; Mello, L. G.; Zanette, D. R.; Sierra, M. M. de S.; Bendo, A.; Quim. Nova 2001, 24, 257.

10. van den Berg, C. M. G. Em Chemical Oceanography; Riley, J. P., ed.; Academic Press: London, 1988.

11. Müller, F. L. L.; Gulin, S. B.; Kalvøy, A.; Mar. Chem. 2001, 76, 233.

12. Kovacevic, Z. L.; Sipos L.; Talanta 1998, 45, 843.

13. Balconi, M. L.; Borgarello, M.; Ferraroli, R.; Realini, F.; Anal. Chim. Acta 1992, 261, 295.

14. Lamble, K. J.; Hill, S. J.; Analyst 1998, 123, 103R.

15. Braungardt, C.; Achterberg, E. P.; Nimmo, M.; Anal. Chim. Acta 1992, 377, 205.
16. Achterberg, E. P.; van den Berg, C. M. G.; Anal. Chim. Acta 1994, 291, 213.

17. Klán, P.; Literák, J.; Relich, S.; J. Photochem. Photobiol., A 2001, 143, 49.

18. Iwaguch, S; Matsumura, K.; Tokuoka, Y.; Wakui, S.; Kawashima, N.; Colloids Surf., B 2002, 25, 299.

19. Walter, P. J.; Chalk, H. M.; Kingston, H. M. Em Microwave Enhanced Chemistry: Fundamentals, Sample Preparation and Applications, Kingstone, H. M.; Haswell, S. J., eds.; ACS: Washington D.C., 2002.

20. Jin, Q.; Liang, F.; Zhang, H.; Zhao, L.; Huan, Y.; Song, D.; TrAC, Trends Anal. Chem. 1999, 18, 479 .

21. Oliveira, E. de; J. Braz. Chem. Soc. 2003, 14,174.

22. Krug, F. J.; I workshop on methods of sample praparation, Piracicaba, Brasil, 1996.

23. Campos, M. L. A. M.; Bendo, A.; Viel, F. C.; Quim. Nova 2002, 25, 808.

24. Benoit, G.; Hunter, K. S.; Rozan, T. F.; Anal. Chem. 1997, 69, 1006.

25. Wang, G. S.; Hsieh, S. T.; Hong, C. S.; Water Res. 2000, 34, 3882

26. Wang, G. S.; Liao, C. H.; Wu, F. J.; Chemosphere 2001, 42, 379.

27. Církva,V.; Hájek, M.; J. Photochem. Photobiol., A 1999, 123, 21.

28. Klán, P.; Literák, J.; Hájek, M.; J. Photochem. Photobiol., A 1999, 128, 145.

29. Sodré, F. F.; Lenzi, E.; Costa, A. C. S. da; Quim. Nova 2001, 24, 324

30. Scarano, G.; Bramanti, E.; Zirino, A.; Anal. Chim. Acta 1992, 24, 123.

31. Buxton, G. V.; Greenstock, C. L.; Helman, W. P.; Ross, A. B.; J. Phys. Chem. Ref. Data 1988, 17, 513.

32. Oliveira, M. C.; Nogueira, R. F. P.; Gomes Neto, J. A.; Jardim, W. F.; Rohwedder, J. J. R.; Quim. Nova 2001, 24, 188.

33. Grassi, M. T.; Sodré, F. F.; J. Phys. IV 2003,107,1283.

34. Windom, H. L.; Byrd, T.; Smith, R. G.; Huan, F.; Environ. Sci. Technol. 1991, 25, 1137 